\title{
The Apolipoprotein E \&2 Allele Is Associated with an Increased Risk of Early-Onset Alzheimer's Disease and a Reduced Survival
}

\author{
Cornelia M. van Duijn, $\mathrm{PhD},{ }^{*}$ Peter de Knijff, PhD, $\dagger$ Anita Wehnert, $\ddagger$ Joke De Voecht,$\ddagger$ \\ Juliana B. Bronzova, MD, ${ }^{*}$ Louis M. Havekes, PhD, $\dagger$ Albert Hofman, MD, PhD, ${ }^{*}$ \\ and Christine Van Broeckhoven, $\mathrm{PhD} \ddagger$
}

It was suggested that in contrast to the $\mathrm{E} 4$ allele, the $\mathrm{E} 2$ allele of the apolipoprotein $\mathrm{E}$ gene $\left(\mathrm{APOE}^{*} 2\right)$ has a protective effect for late-onset Alzheimer's disease and early-onset Alzheimer's disease (EOAD). We studied the role of the $\mathrm{APOE}^{*} 2$ allele in the pathogenesis of EOAD in a Dutch population-based study of 175 probable EOAD patients with onset age at or before 65 years and 532 age-matched controls. In our population, there was no evidence for a protective effect of the APOE* 2 allele on the risk of EOAD. However, our data show that among EOAD patients, survival for APOE* 2 carriers was significantly reduced. When restricting the analysis to patients ascertained early after diagnosis at a stage of disease when mortality is low, our data suggest an increased risk of EOAD for subjects with APOE2E2, APOE2E3, APOE3E4, and APOE4E4 genotypes.

van Duijn C, de Knijff P, Wehnert A, De Voecht J, Bronzova JB, Havekes LM, Hofman A, Van Broeckhoven $C$. The apolipoprotein $\mathrm{E} \varepsilon 2$ allele is associated with an increased risk of early-onset Alzheimer's disease and a reduced survival. Ann Neurol 1995;37:605-610

Apolipoprotein $\mathrm{E}$ (apoE) has three isoforms, apoE- $\varepsilon 2$, apoE- $\varepsilon 3$, and apoE- $\varepsilon 4$. The biosynthesis of these isoforms is fully determined by the apoE gene (APOE) localized at $19 \mathrm{q} 13.2[1,2]$. The $\varepsilon 4$ isoform of apoE has been identified as a factor increasing the risk for early- and late-onset Alzheimer's disease (AD) [3-7]. The risk of $\mathrm{AD}$ associated with the $\mathrm{APOE}^{*} 2$ and APOE* $^{*}$ alleles of the APOE gene is less clear. Corder and associates [8] studied 115 unrelated late-onset $\mathrm{AD}$ (LOAD) patients and observed a significant decrease in LOAD risk for subjects of the APOE2E3 genotype compared with those of the APOE3E3 genotype, the effect being strongest in those with an onset of $\mathrm{AD}$ berween 60 and 66 years. Chartier-Harlin and coworkers $\{6\}$ showed in a population of 34 patients with sporadic early-onset AD (EOAD) and 36 patients with sporadic LOAD, a significant protective effect of the APOE*2 allele. Although a number of studies confirmed the lowered $\mathrm{APOE}^{*} 2$ allele frequency in $\mathrm{AD}$ patients versus controls $[9,10]$, the association was not found by others. One study reported a significant increase in the frequency of the APOE* 2 allele in Italian patients with sporadic $A D$ as well as in familial EOAD [11]. An increased APOE*2 frequency was also reported for $A D$ patients of African-American descent, while a decreased $\mathrm{APOE}^{*} 2$ frequency was found in caucasian $\mathrm{AD}$ patients [12].

We have studied the APOE genotype in relation to risk and survival in 175 patients with clinically diagnosed EOAD and 532 age-matched controls. Earlier we reported a significant association between the APOE* 4 allele and the risk of EOAD in the same population of EOAD patients [7]. The emphasis of this analysis was on the role of the $\mathrm{APOE}^{*} 2$ allele in the pathogenesis of EOAD.

\section{Materials and Methods \\ Patient Selection}

Patients were derived from a population-based epidemiologic study of EOAD [13]. In four northern provinces of the
From the *Deparment of Epidemiology and Biostatistics, Erasmus University Medical School, Rotterdam, and †TNO, Institute of Prevention and Heaith, Gaubius Laboratory, Leiden, The Netherlands; and $\ddagger$ Neurogenetics Laboratory, Born Bunge Foundation, University of Antwerp (UIA), Department of Biochemistry, Antwerp, Belgium.
Received Oct 27, 1994, and in revised form Jan 3, 1995. Accepted for publication Jan 5, 1995.

Address of correspondence to Prof Dr Van Broeckhoven, Laboratory of Neurogenetics, Born Bunge Foundation, University of Antwerp (UIA), Department of Biochemistry, Universiteitsplein 1, B-2610-Antwerpen, Belgium. 
Netherlands and the area of metropolitan Rotterdam, the study aimed at a complete ascertainment of all EOAD patients in whom the onset of $A D$ was at or before the age of 65 years. Age at onset was defined as the age at which memory loss or changes in behavior were first noted [13]. To obtain a full ascertainment of patients, we asked colleagues in all nursing homes, psychiatric institutions, social-geriatric services, neurologic departments, and computed tomography (CT) facilities in these areas to provide us with the names of all dementia patients in whom the onset was at or before the age of 65 years. All patients were diagnosed with $\mathrm{AD}$ in the period of January 1980 to July 1987. For this study, the diagnosis of probable AD was independently confirmed by two neurologists using a standardized protocol according to the National Institute of Neurological and Communicative Disorders and Stroke-Alzheimer's Disease and Related Disorders Association (NINCDS-ADRDA) criteria for $A D[13,14]$. Included in the study were incident, i.e., newly diagnosed EOAD patients as well as prevalent EOAD patients, who may have suffered from the disease for a variable length of time before inclusion in the study. Of the $175(88 \%)$ patients for whom data on APOE genotype were available, 34 (20\%) were included within 1 year after diagnosis, $29(17 \%) 2$ years after diagnosis, 32 (18\%) 3 years, 18 $(10 \%) 4$ years, and $62(35 \%) 5$ years or more after diagnosis. Patients were followed over time and in 1990 their vital status was last ascertained. The mean follow-up period after diagnosis was 6 years (range, 2-12 yr; SD, 2 yr). Of the 175 patients, $60(34 \%)$ patients had died.

For each patient, a control subject was selected matched for gender, age (within 5 years), and place of residence [13]. These controls were drawn randomly from the population register of the municipality where the patient was living at the time of diagnosis. All controls were screened on cognition and none of them showed symptoms of dementia [13]. Blood for APOE typing was available for $159(80 \%)$ controls. Our preliminary analyses did not show a significant association between the $\mathrm{APOE}^{*} 2$ allele and the risk of EOAD [15]. However, APOE* 2 is a rare allele and, therefore, the lack of association may be explained by the lack of statistical power. To exclude this possibility, we increased the statistical power of our study by including an additional 373 control subjects (164 men and 209 women; mean age, 63 $\mathrm{yr}$; SD, $4.2 \mathrm{yr}$ ). These subjects had been screened for dementia as part of another population-based study conducted in Rotterdam, the Rotterdam Study [16]. None of them had a score lower than 26 on the Mini Mental State Examination [17] or showed symptoms of dementia at the time of the study. The allele frequencies of APOE*2 (9\%), APOE*3 $(74 \%)$, and $\mathrm{APOE}^{*} 4(17 \%)$ in the additional 373 controls did not differ significantly from those of the original 159 controls $[7]$.

For all patients and controls, detailed data on family history of dementia in first degree relatives were collected $[13,16]$. To increase the validity of the family history obtained from a next of kin, the data were verified by a sibling of the patient $[7,13]$. The family history of subjects with no first-degree relatives with dementia was classified as negative and of those with at least one first-degree relative with dementia as positive. In 19 families, AD appeared to be inherited as an autosomal dominant disorder.
DNA Analysis

APOE typing for the 175 EOAD patients and 159 controls of the original case-control study has been described earlier [7]. For the additional 373 controls derived from the Rotterdam Study [16], genomic DNA was used for genotyping. The APOE gene was amplified using the primers and amplification conditions described by Wenham and colleagues [18]. After amplification the polymerase chain reaction (PCR) product was digested with the restriction enzyme Hhal and fragments were separated by electrophoresis on a $5 \%$ agarose gel. APOE alleles were visualized by ethidium bromide staining.

EOAD has been shown to be genetically heterogeneous and may be caused by other genetic loci than APOE, i.e., mutations in the amyloid precursor protein (APP) gene on chromosome 21 or a yet unidentified gene on chromosome 14. These other loci may confound the association to APOE. However, by SSCP or PCR sequencing we found no mutations in exons 16 and 17 of the APP gene in a random sample of 100 patients [7]. A linkage study of 10 informative families with autosomal dominant inheritance showed that in one family EOAD was conclusively linked to chromosome 14 (q24.3). The proband of this family was excluded from the present analysis. In two families linkage to $14 \mathrm{q} 24.3$ could be excluded, while in none of the families $A D$ could be conclusively linked to chromosome 19 or 21 [19].

\section{Statistical Analysis}

Allele frequencies for patients and controls were assessed by counting alleles and calculating sample proportions. The $Z$ statistic was used to compare allele frequencies between groups [20]. Statistical testing was always performed at the conventional significance level (p) of 0.05 . The strength of association between a genotype and the risk of EOAD was estimated as the odds ratio (OR) [21], taking the most frequent genotype, $\mathrm{APOE} 3 \mathrm{E} 3$, as reference. All ORs are adjusted for age, gender, and place of residence by logistic regression analysis and are presented with $95 \%$ confidence intervals $(95 \% \mathrm{CI})$ [21]. In each regression model, all genotypes were included simultaneously.

Kaplan-Meier analysis [22] was used to estimate the survival curves for the various APOE genotypes. Differences in survival curves were tested using Cox's proportional hazards model adjusting for age, gender, and place of residence [23]. Both methods take into account that not every patient was followed until death due to the termination of the follow-up of patients in 1990 . In addition, we adjusted these analyses for the fact that not all patients were included in our study at the time of diagnosis [24]. This phenomenon is referred to as left truncation and may result, if not corrected for, in an overestimation of duration of disease [24].

\section{Results}

The Table shows the APOE genotype distribution for patients and controls, overall and stratified by family history of dementia or gender. There was no significant evidence for a protective effect on the risk of EOAD for those with an APOE2E2, APOE2E3, or APOE2E4 genotype compared with those with the APOE3E3 genotype. In men a statistically significantly increased 
Genotype Frequencies of Apolipoprotein E Gene in Early-Onset Alzbeimer's Disease Patients and Controls

\begin{tabular}{|c|c|c|c|c|c|c|c|c|c|c|c|c|c|c|c|}
\hline \multirow[b]{2}{*}{ Genotype } & \multicolumn{2}{|c|}{ Overall } & \multirow{2}{*}{$\begin{array}{l}\mathrm{OR}^{2} \\
(95 \% \mathrm{Cl})\end{array}$} & \multicolumn{2}{|c|}{ Family History - } & \multirow{2}{*}{$\begin{array}{l}\mathrm{OR}^{\mathrm{a}} \\
(95 \% \mathrm{CI})\end{array}$} & \multicolumn{2}{|c|}{ Family History + } & \multirow{2}{*}{$\begin{array}{l}\mathrm{OR}^{\mathrm{a}} \\
(95 \% \mathrm{CI})\end{array}$} & \multicolumn{2}{|c|}{ Men } & \multirow{2}{*}{$\begin{array}{l}\mathrm{OR}^{\mathrm{a}} \\
(95 \% \mathrm{CI})\end{array}$} & \multicolumn{2}{|c|}{ Women } & \multirow{2}{*}{$\begin{array}{l}\mathrm{OR}^{2} \\
(95 \% \mathrm{CI})\end{array}$} \\
\hline & Patients & Controls & & Patients & Controls & & Patients & Controls & & Patients & Controls & & Patients & Controls & \\
\hline E2E2 & $\begin{array}{l}3 \\
(2 \%)\end{array}$ & $\begin{array}{l}6 \\
(1 \%)\end{array}$ & $\begin{array}{l}2.2 \\
(0.5-9.0)\end{array}$ & $\begin{array}{l}3 \\
(4 \%)\end{array}$ & $\begin{array}{l}6 \\
(1 \%)\end{array}$ & $\begin{array}{l}3.8 \\
(0.9-15.7)\end{array}$ & $\begin{array}{l}0 \\
(0 \%)\end{array}$ & $\begin{array}{l}0 \\
(0 \%)\end{array}$ & $-^{b}$ & $\begin{array}{l}2 \\
(3 \%)\end{array}$ & $\begin{array}{l}2 \\
(1 \%)\end{array}$ & $\begin{array}{l}5.4 \\
(0.8-35.0)\end{array}$ & $\begin{array}{l}1 \\
(1 \%)\end{array}$ & $\begin{array}{l}4 \\
(1 \%)\end{array}$ & $\begin{array}{l}0.9 \\
(0.1-8.0)\end{array}$ \\
\hline $\mathrm{E} 2 \mathrm{E} 3$ & $\begin{array}{l}22 \\
(13 \%)\end{array}$ & $\begin{array}{l}88 \\
(17 \%)\end{array}$ & $\begin{array}{l}1.4 \\
(0.8-2.5)\end{array}$ & $\begin{array}{l}10 \\
(15 \%)\end{array}$ & $\begin{array}{l}67 \\
(17 \%)\end{array}$ & $\begin{array}{l}1.1 \\
(0.5-2.4)\end{array}$ & $\begin{array}{l}12 \\
(11 \%)\end{array}$ & $\begin{array}{l}21 \\
(15 \%)\end{array}$ & $\begin{array}{l}1.4 \\
(0.6-3.1)\end{array}$ & $\begin{array}{l}12 \\
(20 \%)\end{array}$ & $\begin{array}{l}37 \\
(16 \%)\end{array}$ & $\begin{array}{l}2.5^{c} \\
(1.1-5.7)\end{array}$ & $\begin{array}{l}10 \\
(9 \%)\end{array}$ & $\begin{array}{l}51 \\
(17 \%)\end{array}$ & $\begin{array}{l}0.7 \\
(0.3-1.5)\end{array}$ \\
\hline E2E4 & 1 & $\begin{array}{l}10 \\
(2 \%)\end{array}$ & $\begin{array}{l}0.4 \\
(0.1-3.0)\end{array}$ & $\begin{array}{l}1 \\
(2 \%)\end{array}$ & $\begin{array}{l}4 \\
(1 \%)\end{array}$ & $\begin{array}{l}1.4 \\
(0.2-12.0)\end{array}$ & $\begin{array}{l}0 \\
(0 \%)\end{array}$ & $\begin{array}{l}6 \\
(4 \%)\end{array}$ & $\begin{array}{l}0 \\
(0.0-3.4)\end{array}$ & $\begin{array}{l}0 \\
(0 \%)\end{array}$ & $\begin{array}{l}7 \\
(3 \%)\end{array}$ & $\begin{array}{l}0 \\
(0.0-8.0)\end{array}$ & $\begin{array}{l}1 \\
(1 \%)\end{array}$ & $\begin{array}{l}3 \\
(1 \%)\end{array}$ & $\begin{array}{l}0.8 \\
(0.1-7.4)\end{array}$ \\
\hline E3E3 & $\begin{array}{l}58 \\
(33 \%)\end{array}$ & $\begin{array}{l}273 \\
(51 \%)\end{array}$ & $\begin{array}{l}1 \\
\text { Reference }\end{array}$ & $\begin{array}{l}28 \\
(41 \%)\end{array}$ & $\begin{array}{l}207 \\
(53 \%)\end{array}$ & $\begin{array}{l}1 \\
\text { Reference }\end{array}$ & $\begin{array}{l}30 \\
(28 \%)\end{array}$ & $\begin{array}{l}66 \\
(48 \%)\end{array}$ & $\begin{array}{l}1 \\
\text { Reference }\end{array}$ & $\begin{array}{l}18 \\
(31 \%)\end{array}$ & $\begin{array}{l}110 \\
(48 \%)\end{array}$ & $\begin{array}{l}1 \\
\text { Reference }\end{array}$ & $\begin{array}{l}40 \\
(35 \%)\end{array}$ & $\begin{array}{l}163 \\
(53 \%)\end{array}$ & $\begin{array}{l}1 \\
\text { Reference }\end{array}$ \\
\hline E3E4 & $\begin{array}{l}62 \\
(35 \%)\end{array}$ & $\begin{array}{l}144 \\
(27 \%)\end{array}$ & $\begin{array}{l}2.0^{c} \\
(1.3-3.1)\end{array}$ & $\begin{array}{l}19 \\
(28 \%)\end{array}$ & $\begin{array}{l}102 \\
(26 \%)\end{array}$ & $\begin{array}{l}1.4 \\
(0.8-2.7)\end{array}$ & $\begin{array}{l}43 \\
(40 \%)\end{array}$ & $\begin{array}{l}42 \\
(30 \%)\end{array}$ & $\begin{array}{l}2.4^{c} \\
(1.3-4.3)\end{array}$ & $\begin{array}{l}20 \\
(34 \%)\end{array}$ & $\begin{array}{l}66 \\
(29 \%)\end{array}$ & $\begin{array}{l}2.2^{\mathrm{c}} \\
(1.1-4.4)\end{array}$ & $\begin{array}{l}42 \\
(36 \%)\end{array}$ & $\begin{array}{l}78 \\
(26 \%)\end{array}$ & $\begin{array}{l}2.1^{c} \\
(1.3-3.5)\end{array}$ \\
\hline $\mathrm{E} 4 \mathrm{E} 4$ & $\begin{array}{l}29 \\
(17 \%)\end{array}$ & $\begin{array}{l}11 \\
(2 \%)\end{array}$ & $\begin{array}{l}16.6^{\circ} \\
(6.9-40.0)\end{array}$ & $\begin{array}{l}7 \\
(10 \%)\end{array}$ & $\begin{array}{l}7 \\
(2 \%)\end{array}$ & $\begin{array}{l}8.6^{\mathrm{c}} \\
(2.8-26.4)\end{array}$ & $\begin{array}{l}22 \\
(21 \%)\end{array}$ & $\begin{array}{l}4 \\
\langle 30 y\end{array}$ & $\begin{array}{l}12.4^{c} \\
(4.2-36.5)\end{array}$ & $\begin{array}{l}7 \\
(12 \%)\end{array}$ & $\begin{array}{l}6 \\
(3 \%)\end{array}$ & $\begin{array}{l}9.2^{c} \\
(2.8-30.8)\end{array}$ & $\begin{array}{l}22 \\
(19 \%)\end{array}$ & $\begin{array}{l}5 \\
(2 \%)\end{array}$ & $\begin{array}{l}17.0^{c} \\
\langle 6.4-44.8\}\end{array}$ \\
\hline Total & $\begin{array}{l}175 \\
(100 \%)\end{array}$ & $\begin{array}{l}532 \\
(100 \%)\end{array}$ & & $\begin{array}{l}68 \\
(100 \%)\end{array}$ & $\begin{array}{l}393 \\
(100 \%)\end{array}$ & & $\begin{array}{l}107 \\
(100 \%)\end{array}$ & $\begin{array}{l}139 \\
(100 \%)\end{array}$ & & $\begin{array}{l}59 \\
(100 \%)\end{array}$ & $\begin{array}{l}228 \\
(100 \%)\end{array}$ & & $\begin{array}{l}116 \\
(100 \%)\end{array}$ & $\begin{array}{l}304 \\
(100 \%)\end{array}$ & \\
\hline
\end{tabular}

Odds ratio (OR) with $95 \%$ confidence incerval $(95 \% \mathrm{CI}$ )

${ }^{b} \mathrm{No}$ estimation of the odds ratio due to a division by 0 .

'Odds ratio statistically significantly $(p<0.05)$ increased.

risk was found for those with the APOE2E3 genotype. When pooling the APOE2E2, APOE2E3, and APOE2E4 genotypes, the risk associated with the APOE* 2 allele was nonsignificant in the overall analysis $(\mathrm{OR}=1.2$ with $95 \% \mathrm{CI} 0.7-2.0)$ and in all subgroup analyses (family history -: OR $=1.4$ with $95 \% \mathrm{CI}$ $0.7-2.7$; family history $+: \mathrm{OR}=1.0$ with $95 \% \mathrm{CI}$ $0.4-2.2$; men: $\mathrm{OR}=1.9$ with $95 \% \mathrm{CI} 0.9-4.1$ and women $\mathrm{OR}=0.8$ with $95 \% \mathrm{CI} 0.4-1.7$ ).

There was no statistically significant difference in $\mathrm{APOE}^{*} 2$ allele frequency between cases $(8 \%)$ and controls $(10 \%)$. Among patients, the $\mathrm{APOE}^{*} 2$ allele frequency was related to the duration of illness at ascertainment. Figure 1 shows that within a period of 2 years following diagnosis, the APOE* 2 allele frequency was higher in EOAD patients compared with controls (14-15\% vs $10 \%$ ), while 3 years or more after diagnosis the APOE* 2 allele frequency was lower in EOAD patients $(3-8 \%)$. This finding suggests that survival of EOAD patients carrying one or more $\mathrm{APOE}^{*} 2$ alleles is reduced. In contrast, the $\mathrm{APOE}^{*} 4$ allele frequency did not show a consistent decrease in time (see Fig 1). Independent of the duration of EOAD at ascertainment, the APOE* 4 allele frequency in EOAD patients $(25-45 \%)$ was always higher among EOAD patients than among controls (17\%).

To test whether patients' survival was influenced by the APOE genotype, we compared survival curves of EOAD patients with different APOE genotypes (Fig 2). Mortality was highest in APOE*2 carriers and lowest in APOE*4 carriers. A significant $2.195 \% \mathrm{CI}$ 1.1-4.3)-fold reduction in survival for $\mathrm{APOE}^{*} 2$ carriers compared with APOE3E3 carriers was calculated. Although survival curves for APOE* 4 and APOE3E3 carriers crossed at 121 months after diagnosis, the survival rate for APOE4E4 carriers remained significantly increased over time. For $56(93 \%)$ of the 60 patients that died during the period of follow-up, information about the cause of death was available. Of the 16 deceased $\mathrm{APOE}^{*} 2$ carriers, sepsis, pneumonia, infection diseases, cachexia, and dehydration were reported as the cause of death in $10(63 \%)$. These are secondary complications that are commonly observed during the terminal stage of $\mathrm{AD}$. Three (19\%) patients died of cardiovascular disease and $2(13 \%)$ of cancer. Cause of death was unknown in $1(6 \%)$ parient. Of the 22 deceased $\mathrm{APOE}^{*} 4$ carriers, the cause of death was unknown for $2(9 \%) ; 15(68 \%)$ died of secondary complications similar to those reported for the $\mathrm{APOE}^{*} 2$ carriers, $4(18 \%)$ of cardiovascular disease, and $1(5 \%)$ of cancer. When comparing the death causes of APOE*2 and $\mathrm{APOE}^{*} 4$ carriers with those of the 22 deceased APOE3E3 carriers, no significant differences were observed.

To adjust for possible biases due to the differential survival of patients related to their APOE genotype, we restricted the analysis to patients included in the study within 2 years after diagnosis. In this period, mortality among patients was low (see Fig 2) and, thus, no effect of differential survival is expected. Genotype frequencies of the selected $63 \mathrm{EOAD}$ patients were APOE2E2 $3 \%$, APOE2E3 21\%, APOE2E $42 \%$, APOE3E3 $17 \%$, APOE3E4 $35 \%$, and APOE4E 4 $22 \%$. Compared with the frequencies of controls (see Table), the risk of EOAD was statistically significantly increased for the APOE2E2 (OR $=7.1$; $95 \%$ CI $1.3-37.8$ ), APOE2E3 (OR $=3.6 ; 95 \% \mathrm{CI}$ 1.6-8.3), APOE3E4 (OR $=3.8 ; 95 \%$ CI 1.8-8.1), and APOE4E4 (OR $=33.0 ; 95 \% \mathrm{CI} 12.4-88.4)$ genotypes. The risk associated with the APOE2E4 genotype was nonsignificantly increased $(\mathrm{OR}=2.3$; 95\% CI 0.3-19.7). 

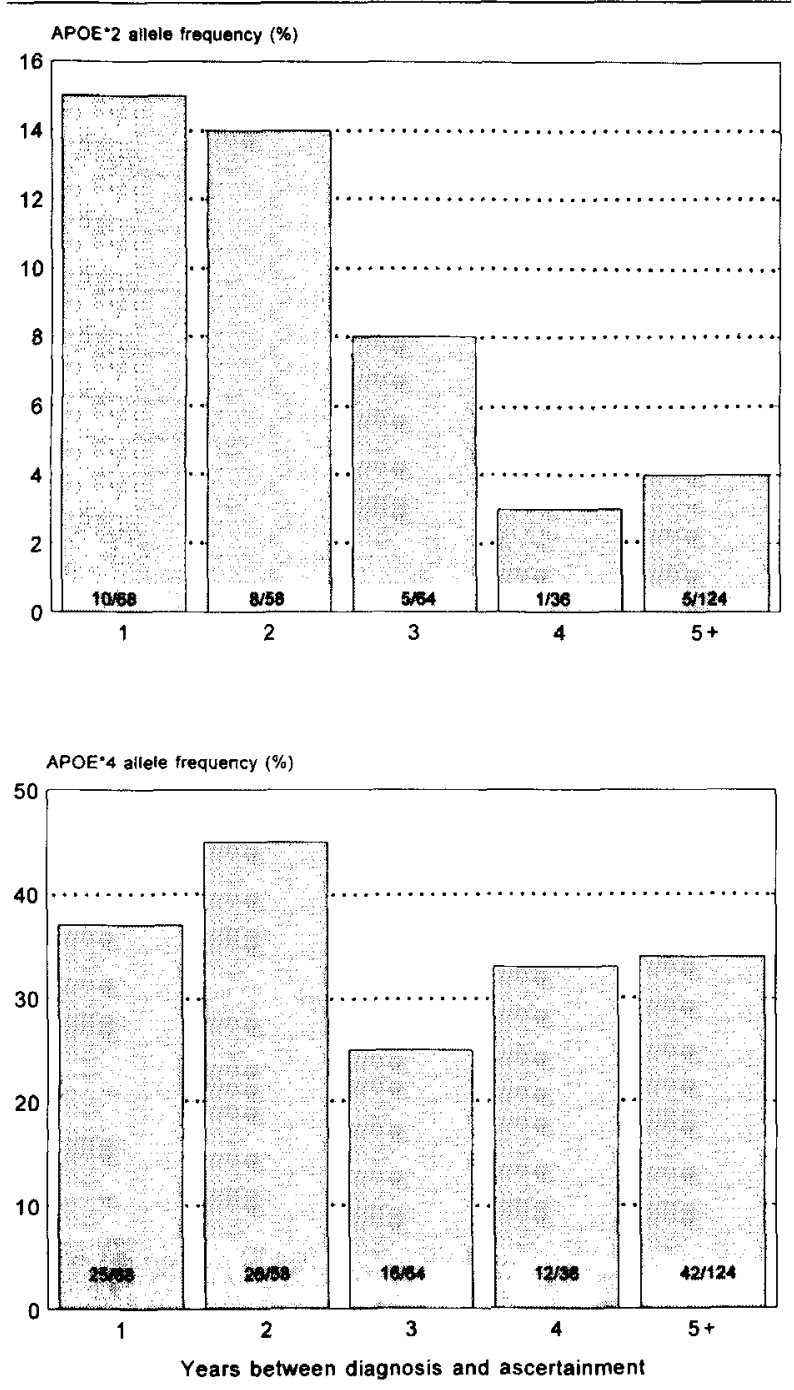

Fig 1. Allele frequencies of $A P O E^{*} 2$ and $A P O E^{*} 4$ in earlyonset Alzheimer's disease (EOAD) patients by the number of years between diagnosis of EOAD and ascertainment of the patient. The number of apolipoprotein $E$ alleles and the total number of alleles are given within the bars. Since each patient has two alleles, the total number of alleles equals double the number of patients.

\section{Discussion}

In our population, EOAD patients who carry APOE*2 have a significantly reduced survival after diagnosis. When restricting the analysis to patients ascertained early after diagnosis at a stage of disease when mortality is low, our data suggest an increased risk of EOAD for subjects with APOE2E2, APOE2E3, APOE3E4, and APOE4E4 genotypes. Allelic association may result from (1) population admixture, which implies bias has occurred because the study population is a mixture of populations with different APOE allele as well as AD frequencies, (2) a direct role of $\mathrm{APOE}$ in the $\mathrm{AD}$ pathogenesis, or (3) linkage disequilibrium, which im- plies that the risk allele of an unknown causal gene always is accompanied by the APOE*2 or $\mathrm{APOE}^{*} 4$ allele, because APOE and the causal gene are close together on chromosome 19 and recombination during meiosis is unlikely.

Although population admixture can never be fully excluded, it is unlikely that it occurred in our population as all patients and controls were derived from a homogeneous white population and were matched for residence. Evidence for the second explanation, a direct biological role of $\mathrm{APOE}$ in the $\mathrm{AD}$ pathogenesis is derived from studies suggesting a crucial role of APOE in $\beta A 4$ amyloid deposition in senile plaques and angiopathy [25]. It has been suggested that this process is accelerated in $\mathrm{APOE}^{*} 4$ carriers because apoE4 binds more readily to $\beta A 4$ amyloid, making it less soluble $[3,26]$. Whether apoE2 also interferes with $\beta A 4$ amyloid depositions remains to be proven. On the other hand, there is also some evidence for the third explanation, linkage disequilibrium, in which case APOE will be associated with the EOAD risk, although it is not implicated in the AD pathogenesis itself. It has been shown that the APOE gene is in linkage disequilibrium with neighboring genes [27] and an association of APOE with EOAD and LOAD with polymorphic markers flanking the APOE gene has been reported [6,28]. A typical feature of linkage disequilibrium is that in different populations, different alleles may be associated to the disease. APOE* 4 has been consistently shown to be a risk factor for $\mathrm{AD}$ in the present and earlier studies [3-12]. However, the differential effect of $\mathrm{APOE}^{*} 2$ on $\mathrm{AD}$ risk in different populations is compatible with linkage disequilibrium $[6,8-12]$.

In addition to linkage disequilibrium, there are several other explanations for the discrepancy between studies of the role of APOE*2 in AD possible. In the subgroup of EOAD patients, genes other than APOE may confound studies. This explanation for the lack of a protective effect of $\mathrm{APOE}^{*} 2$ for EOAD is less likely in our study. A protective effect of $\mathrm{APOE}^{*} 2$ for EOAD has been shown by Chartier-Harlin and associates [6]; and in the study of Corder and colleagues [8] the AD patients with an early onset age, i.e., between 60 and 66 years, showed the strongest evidence for a protective effect. In contrast, we did not find evidence for a reduced risk of $A D$ associated with the APOE2E3 genotype when we analyzed only EOAD patients belonging to this age category $(\mathrm{OR}=1.7$ with $95 \% \mathrm{CI}$ 0.7-4.6). Further, the APOE*4 [7] nor the APOE*2 allele frequency was associated with age-at-onset in our EOAD patients, suggesting a similar association of APOE* 4 and APOE* 2 to the risk of EOAD in all age categories up to 65 years. Another explanation may be that mutations may have occurred in the rare APOE*2 allele that lead to an increased risk of $A D$. The new 


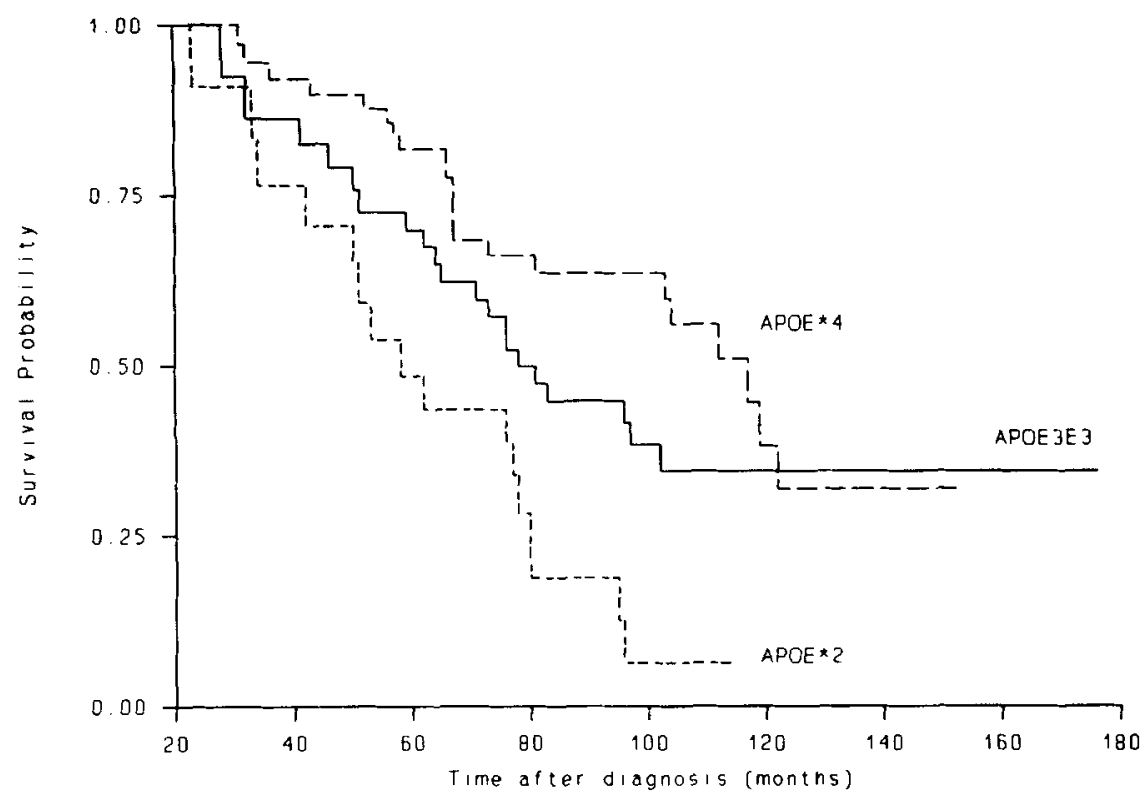

Fig 2. Survival of early-onset Alzbeimer's disease patients by apolipoprotein $E$ (APOE) genotype. Included are 58 subjects of the APOE $3 E 3$ genotype, 91 APOE*4 carriers, and 25 APOE*2 carriers. One subject of the APOE2E4 genotype bas been excluded.

APOE alleles resulting from such mutations may be important determinants of $A D$ risk in some populations but not in others, e.g., because of genetic drift. Such a mechanism cannot be excluded unless the APOE gene is fully sequenced in all patients. Furthermore, other genes or environmental factors may modify the expression of APOE resulting in differences berween populations. In this light, our finding that the increased risk of EOAD for APOE*2 carriers was strongest in men is of interest, as men may have a different profile of environmental exposure than women, particularly with regard to cardiovascular factors.

Our finding of a reduced survival of EOAD patients with an $\mathrm{APOE}^{*} 2$ allele contributes another explanation to the controversial findings. Studies of prevalent patients, which include patients who suffer from the disease for an indefinite number of years, tend to exclude early fatalities and therefore are likely to overrepresent patients who survive longer [29]. Bias may occur in particular when the risk factor studied is associated with survival [29]. When EOAD patients with one or two $\mathrm{APOE}^{*} 2$ alleles have a reduced survival, $\mathrm{APOE}^{*} 2$ carriers may have been selectively removed from the patient population over time. This may result in an artificial decrease of the $\mathrm{APOE}^{*} 2$ allele frequency and subsequently in an artificial decrease in risk associated with $\mathrm{APOE}^{*} 2$ when patients are compared with controls. The shift over time in the APOE* 2 allele fre- quency in our EOAD patient population supports the view that reduced survival of $\mathrm{APOE}^{*} 2$ carriers may bias risk estimation in a population of prevalent EOAD patients. In a similar way, the increased survival of APOE4E4 carriers may have led to an overrepresentation of $\mathrm{APOE}^{*} 4$ carriers. Adjusting for the differential survival by genotype by restricting the analysis to a period in which mortality was negligible, our study suggests that the $\mathrm{APOE}^{*} 2$ and $\mathrm{APOE}^{*} 4$ allele are both genetic risk factors for EOAD.

The $\mathrm{APOE}^{*} 2$ allele has been associated with longevity in a population of centenarians [30]. Our finding that patients carrying an $\mathrm{APOE}^{*} 2$ allele have a reduced survival therefore suggests that the apoE2 protein, or perhaps a protein in disequilibrium, may accelerate the pathological process underlying EOAD. This finding is in line with the increased risk of EOAD that we found for APOE*2 carriers. An important issue to resolve, however, is the apparently contradictory finding that the APOE4E 4 genotype is associated with an increased EOAD risk $[6,7]$ as well as with a prolonged survival of EOAD patients. Although our data and those of others suggest that clinically APOE genotypes may be used as predictors of $A D$ risk and survival, many questions on the role of APOE in the pathogenesis of $\mathrm{AD}$ are still unanswered.

This research was funded by the Flemish Biotechnology Program, The Netherlands Organisation for Scientific Research (NWO), The Netherlands Institute for Health Sciences (NIHES), the Eurodem EC Concerted Action on dementia. CVB is a research associate of the National Fund for Scientific Research (NFSR), Belgium. The Rotterdam Study was supported in part by the NESTOR programme for geriatric tesearch (Ministry of Health and Ministry of Education), 
The Netherlands Heart Foundation, The Netherlands Organisation for Scientific Research (NWO), and the Municipality of Rotterdam.

We thank Drs Wim Schulte, Teun Tanja, Rob Haaxma, Arie Lameris, and Rolf Saan for assisting with case diagnosis and Helen de Bruijn, Micheline de Haes, Jeanette Kamman, Hilda Kornman, Hanneke van Meurs, and Caroline Valkenburg for genealogy studies. Hans van der Boom is acknowledged for apoE isotyping.

\section{References}

1. Das HK, McPherson J, Brun GAP, et al. Isolation characterization, and mapping to chromosome 19 of the human apolipoprotein E gene. J Biol Chem 1985;260:6240-6247

2. Olaisen B, Teisberg P, Gedde-Dahl T. The locus for apolipoprotein $\mathrm{E}$ (apoE) is linked to the complement component $\mathrm{C} 3$ (C3) locus in chromosome 19 in man. Hum Genet 1982;62: $233-236$

3. Strittmatter WJ, Saunders AM, Schmechel D, et al. Apolipoprotein E: high avidity binding to beta-amyloid and increased frequency of type 4 allele in late-onset familial Alzheimer's disease. Proc Natl Acad Sci USA 1993;90:1977-1981

4. Saunders AM, Strittmatter WJ, Schmechel D, et al. Association of apolipoprotein $\mathrm{E}$ allele $\varepsilon 4$ with late-onset familial and sporadic Alzheimer's disease. Neurology 1993;43:1467-1472

5. Corder EH, Saunders AM, Strittmatter WJ, et al. Gene dose of apolipoprotein $\mathrm{E}$ type 4 allele and the risk of Alzheimer's disease in late onset families. Science 1993;261:921-923

6. Chartier-Harlin MC, Parfitt M, Legrain S, et al. Apolipoprotein E, E4 allele as a major risk factor for sporadic early and lateonset form of Alzheimer's disease: analysis of the 19q13.2 chromosomal region. Hum Mol Genet 1994;3:569-574

7. van Duijn CM, de Knijff P, Cruts M, et al. Apolipoprotein E4 allele in a population-based study of early-onset Alzheimer's disease. Narure Genet 1994;7:74-78

8. Corder EH, Saunders AM, Risch NJ, et al. Protective effect of apolipoprotein $\mathbf{E}$ type 2 allele for late onset Alzheimer disease. Nature Genet 1994;7:180-184

9. West HL, Rebeck W, Hyman BT. Frequency of the apolipoprotein $\mathrm{E} \varepsilon 2$ allele is diminished in sporadic Alzheimer disease. Neurosci Lett 1994;175:46-48

10. Talbot C, Lendon C, Craddock N, et al. Protection against Alzheimer's disease with apoE $\varepsilon 2$. Lancet 1994;343:1432-1433

11. Sorbi S, Nacmias B, Forleo P, et al. ApoE allele frequencies in Italian sporadic and familial Alzheimer's disease. Neurosci Let 1994;177:100-102

12. Maestre G, Ottman R, Stern Y, et al. Apolipoprotein E and Alzheimer's disease: ethnic variation in genotypic risks. Ann Neurol 1995;37:254-259

13. Hofman A, Schulte W, Tanja TA, et al. History of dementia and Parkinson's disease in 1st-degree relatives of patients with Alzheimer's disease. Neurology 1989;39:1589-1592

14. McKhann G, Drachman D, Folstein M, et al. Clinical diagnosis of Alzheimer's disease: report of the NINCDS-ADRDA work group. Neurology 1984;34:939-944

15. van Duijn CM, de Knijff $\mathbf{P}$, Cruts $\mathbf{M}$, et al. The apolipoprotein $\mathrm{E}$ gene and the risk of early-onset Alzheimer's disease. In: Iqbal K, Mortimer JA, Winblad B, Wisniewski HM, eds. Research advances in Alzheimer's disease and related disorders. Chichester: John Wiley and Sons, 1995:97-101

16. Hofman A, Grobbee DE, DeJong PTVM, Vandenouweland FA. Determinants of disease and disability in the elderly. The Rotterdam elderly study. Eur J Epidemiol 1991;7:403-422

17. Folstein MF, Folstein SE, McHugh PR. Mini-Mental State: a practical method for grading the cognitive state of patients for the clinician. J Psychiatr Res 1975;12:189-198

18. Wenham PR, Price WH, Blundell G. Apolipoprotein E genotyping by one-stage PCR. Lancet 1991;337:1158-1159

19. van Duijn CM, Hendriks L, Farrer LA, et al. A popularion-based study of familial Alzheimer's disease: Linkage to chromosomes 14, 19 and 21. Am J Hum Genet 1994;55:714-727

20. Elston RC, Johnson WD. Essentials of biostatistics. Philadelphia: Davis, 1987

21. Schlesselman JL. Case-control studies. New York: Oxford University Press, 1982

22. Kaplan EL, Meier P. Non parametric estimation for incomplete observations. J Am Stat Assoc 1958;53:457-481

23. Cox DR. Regression models and life tables. J R Stat Soc 1972; $34: 187-220$

24. Kurtzke JF. On estimating survival; a tale of two censors. J Clin Epidemiol 1989;42:169-175

25. Hardy JA, Higgings GA. Alzheimer's disease: the amyloid cascade hypothesis. Science 1992;256:184-185

26. Schmechel D, Saunders AM, Strittmatter WJ, et al. Increased amyloid $\beta$-pepride deposition in cerebral cortex as a consequence of apolipoprotein E genotype in late-onset Alzheimer's disease. Proc Natl Acad Sci USA 1993;90:9649-9653

27. Houlston RS, Snowden C, Green F, et al. Apolipoprotein (apo) $\mathrm{E}$ genotypes by polymerase chain reaction and allele-specific oligonucleotide probes: no detectable linkage disequilibrium between apoE and apoCII. Hum Genet 1989;83:364-368

28. Schellenberg GD, Boehnke M, Wijsman EM, et al. Genetic association and linkage analysis of the apolipoprotein CII locus and familial Alzheimer's disease. Ann Neurol 1992;3:223-227

29. Miettinen OS. Theoretical epidemiology: principles of occurrence research in medicine. New York: John Wiley and Sons, 1985

30. Schächter F, Faure-Delanef L, Guénot F, et al. Genetic associations with human longevity at the APOE and ACE loci. Nature Genet 1994;6:29-33 